\title{
La imagen moderna: Renacimiento y Modernismo a través de la metamorfosis
}

\author{
The modern image: Renaissance and Modernism through metamorphosis
}

Francisco José Casado Pérez

Conservación y Restauración de Bienes Culturales Inmueble, Escuela Nacional de Conservación, Restauración y Museografía "Manuel del Castillo Negrete”, México (francisco_casado_p@encrym.edu.mx)

RESUMEN: La iconografía es un estudio complejo que busca recorrer los intrincados caminos de las imágenes, las cuales, como todo conocimiento, están supeditadas al cambio. Esta idea nos conduce a ver el concepto de metamorfosis como un posible fundamento para el análisis iconográfico, especialmente de dos momentos sumamente afines a este concepto: el Renacimiento y el Modernismo. Ambos aparentan una yuxtaposición, pero en realidad se vinculan entre sí por un hilo invisible, punto esencial del análisis. Por consiguiente, este planteamiento tiene por objetivo la búsqueda de reinterpretaciones con el fin de expandir el horizonte de conocimientos iconográficos y adentrarse en la esencia de los imaginarios culturales que heredamos y que eventualmente transmitiremos a las siguientes generaciones.

PALABRAS CLAVE: Renacimiento, modernismo, iconografía, metamorfosis.

\begin{abstract}
Iconography is a complex assignment that travels the intrincate paths of the images, which, like all knowledge, are tied to change. Such idea leads us to see the concept of methamorphosis as a possible basis for the iconographic analysis, especially of two moments highly related to this concept: the Renaissance and Modernism. Both appear to be juxtapossed, but in reality they are linked together by an invisible thread, the essential point of the analysis. Therefore, this approach's objective is to search some reinterpretations in order to expand the horizon of iconographic knowledge and to enter into the essence of the cultural imaginaries that we inherit and that evenually we'll transmit to the following generations.
\end{abstract}

KEYWORDS: Renaissance, modernism, iconography, metamorphosis. 
Al pensar en la palabra metamorfosis, una de las primeras referencias que resaltan está en la literatura, sin embargo, ello enfrenta una disyuntiva de los siglos. En el extremo más antiguo se encuentra Ovidio, mientras que en el contemporáneo está Kafka. A pesar de que el contexto general de ambos difiere por creces, el concepto de metamorfosis les une. Ambos coinciden en el hecho de que el hombre -0 la visión sobre éste- tiende a cambiar, a transformarse, con base en las circunstancias y factores presentes; podría decirse que responde a un modo de supervivencia: adaptarse o morir. Al igual que ellos, la idealización de la imagen moderna como extensión del hombre y sus valores, también le ha sobrevenido una serie de metamorfosis a lo largo del tiempo, con el fin de darle presencia y pertenencia en el tránsito imparable del tiempo que Perilli (2008, p.18) sintetiza perfectamente: "El primer verso de las Metamorfosis de Ovidio recita: In nova fert animus dicere formas / corpa (El ánimo mueve a decir las formas mudadas a nuevos cuerpos). No son los cuerpos buscando formas nuevas, sino las formas buscando cuerpos nuevos".

Sin embargo, en la obra de ambos literatos ¿cómo pudo llevarse a cabo la transformación de sus las respectivas imágenes que heredaron?, si “...las imágenes se atraen, nos atraen, nos convencen de que son lo que aparentan, son la historia de Narciso y Medusa. Y su fuerza es también la inmediatez” (Ibíd., p. 15), ¿de qué manera actúa la metamorfosis en estos tránsitos? Tal cometido inicia con la coyuntura: tenemos dos extremos, pero el hilo intermedio (Ibíd., p, 18) es el que debe recorrerse, es hacer un viaje a través del cambio.

\section{Similitudes y mitos}

Si se conjetura que los hitos corresponden a los respectivos pasados y presentes, el hilo es un caso aparte. Para el cual se requerirá que primero nos adelantemos un poco en el tiempo hasta mediados del siglo XX, debido a que el proceso de metamorfosis, que podría denominarse de expansión iconográfica, puede interpretarse a partir del concepto las cuatro similitudes que Michel Foucault menciona en Las palabras y las cosas (1968), las cuales se precisan a continuación:

- Convenientia: "semejanza ligada al espacio..." (Foucault, 2005, p.27); similitud relacionada a la proximidad e interrelación directa y recíproca entre ambos elementos: cielo y tierra, mar y playa.

- Aemulatio: “...conveniencia que estaría libre de la ley del lugar y jugaría, inmóvil, en la distancia...una semejanza sin contacto" (Ibíd. p.28); reflejo o repetición física y metafórica 
de un original sin importar la ubicación en que su réplica tenga en el mundo. Guardan similitud pero no dependen uno del otro más que de génesis.

- Analogía: “...se superponen la convenientia y la aemulatio... [es un] enfrentamiento de las semejanzas a través del espacio...basta con que sean las semejanzas más sutiles de las relaciones" (Ibíd. p.30); una similitud emuladora, donde la réplica asemeja al original con respecto a la interrelación de ésta

- Sympathia: "Aquí no existe ningún camino determinado de antemano, ninguna distancia está supuesta, ningún encadenamiento prescrito...provoca los acercamientos más distantes” (Ibíd. p.32); vínculo asimilador donde cada objeto del conjunto convive e interactúa “ “...conservando su singularidad” (Ibíd. p.33) a pesar de que también permite “...que las cosas se crucen, se desarrollen, se mezclen, desaparezcan, mueran y se recobren indefinidamente" (Ídem.), que, en cierto modo, engloba a las primeras tres similitudes con el fin de mantener al mundo en la dialéctica del orden.

No obstante, Foucault comenta que no basta con las similitudes para conocer a profundidad los objetos que nos rodean, no hay semejanza ni singularidad (Ibíd. p.35), sino que las similitudes están regidas bajo un sistema de signaturas, el cual se describe cómo la interrelación entre lo visible e invisible (Ídem.), hecho que indica y confirma cómo el hombre -quizás, desde el las épocas más primitivas- sostiene una inherente dependencia con las imágenes, especialmente para comunicarse gráfica y oralmente. Además, de que las imágenes que utiliza, precisamente, no surgen del vacío, tienen un trasfondo basado en la asimilación de lo que el artista -y quizás también el receptor- percibe y experimenta a partir de sus sentidos, especialmente la vista, por lo que se requerirá de una imagen concreta para poder percibir las similitudes.

A partir de tales fundamentos puede comprenderse parte del logos de las imágenes renacentistas y modernistas, tanto religiosas como civiles; no obstante, queda un poco endeble la comprensión de íconos fantásticos, resaltemos lo dicho por Perilli: "Las imágenes engañan, no son otra cosa que recuerdo, la sombra de la idea. Así hay que tomarlas, usarlas como migas camino a casa” (2008, p. 15). En consecuencia, en este hilo procesional para el camino a casa, es imperante profundizar en una parte de sus fibras: el mito, especialmente el desarrollado por la práctica didáctica de Platón. Hemos seguido las migas, debemos continuar para volver a casa.

Para este punto retomaremos la figura de Karl Kerényi (1897-1973): filólogo clásico de origen húngaro considerado uno de los fundadores de los estudios modernos sobre mitología griega, quien 
resume al mito como “... un arte unido y consustancial a la poesía (ambos dominios coinciden), un arte con antecedentes materiales particulares" (Jung, 2004, p.17), el cual, de cierto modo reincide en la sentencia previa de la inherente dependencia del hombre con los objetos que encuentra en su medio; sin embargo, no depende únicamente de ello, por el involucramiento primordial de los mitologemas ${ }^{1}$ : elementos (valores, imágenes, ideas, conceptos) que combinan la imaginación con las tradicionales que ayudaron a la determinación de la identidad cultural de un grupo, además del tiempo y el lugar.

En suma, el mito, como un relato, no sólo intenta transmitir un mensaje (especialmente axiológico) a partir de las imágenes utilizadas que refieran a los rasgos culturales propios de un momento (Ibíd. p.18), sino que el carácter del mito es atemporal (Kérenyi, 2009, p.14), debido a que transmite, un trasfondo misterioso que provoca cierta familiaridad, misma que induce a la imaginación y conduce a la reflexión (Ídem.). Aunado a esto, el mito también funciona a manera de nexo inmaterial que desafía tiempo y espacio al conectar distintas generaciones a partir de la memoria y el recuerdo, provocado por la inspiración que inoculan los personajes; véase la fundación de Roma a partir del mito de Rómulo y Remo o lo que en el caso de México es la Tira de la Peregrinación sobre la fundación de México-Tenochtitlán.

No obstante, retomando la figura de la Sympathia de Foucault, durante los cambios a través del paso del tiempo ¿qué sucede con los valores? Nuevamente, recurriendo a Perilli, éste comenta: "Las ideas son personas cercanas, siempre regresan a lo mismo, a la rutina del cariño. [Y] El arte es la orden de no obedecer a la perfección de una armonía hereditaria" (2008, p.13). Sin embargo, la respuesta más fidedigna no está como se mencionó en el regreso, sino que va en sentido de la ambigüedad, puede o no cambiar, y ello es debido a que lo que he comentado sobre los valores, que al ser "...condiciones, tanto a nivel individual como social. Son razón y resultante del hombre, como de sus acciones, las cuales, pueden ser analizadas en relación a los parámetros establecidos en su propia temporalidad de origen y su evolución...” (Casado, 2017, p.43). Por lo tanto, las imágenes, como sus valores, están sujetos a un metamórfico trajinar, de forma y significado, hecho que puede verse en un sinfín de épocas y sitios. Pero, sobre todo, esta interesante visión interpretativa tiene dos momentos de gran referencia, dos épocas fundamentales para el mundo, que para efectos del presente artículo, fueron la vívida representación de la metamorfosis: el Renacimiento y el Modernismo.

\footnotetext{
${ }^{1}$ Definición acuñada por Kerényl.
} 


\section{Tránsito metamórfico del Renacimiento}

El desarrollo del concepto moderno, tiene dos vertientes primordiales. La primera surgió como fundamento en el estandarte del Renacimiento, con el cual se encaminaría a la humanidad -a partir de los valores socio-culturales- a un proceso de reconfiguración en donde el hombre se concebía nuevamente, pero ahora a manera de metáfora, como el centro del universo, donde "el hombre es libertad, el mundo no humano, necesidad; el hombre es foco de actividad dirigida a los objetos; el mundo, su correlato" (Villoro, 2015, p.166). Ideal que le determinaría como principio y fin de todo desarrollo material. Mientras que, en el caso de la modernidad, tan propia del siglo XIX como de algunos destellos de la actualidad, sería más un modo de vida que un estandarte, aunque ciertamente continuó con el ideal del hombre como epicentro.

Sin embargo, debido a la acumulación del progreso técnico y el crecimiento de las poblaciones, se propiciaron tensiones y rupturas en diversos ámbitos humanos, especialmente en el arte y la economía, dando "con la representación de un refinamiento excesivo, de una artificialidad extrema y de una supercivilización. Explicación verdadera y falsa a la vez y en todo caso superficial..." (Lefebvre, 1971, pp. 163-164). Ambos momentos preconizaron una revolución total del mundo en sus respectivos momentos y por lo tanto cada uno necesitó de un modelo iconográfico propio con el cual identificarse entre sus contemporáneos y con sus sucesores.

En este punto, cabe recalcar que la descendencia directa entre moderno y modernismo, radica en que ambos recurrieron al mismo marco de la metamorfosis, por consiguiente daremos paso al análisis lógico deductivo de cada momento a partir de las similitudes previamente expuestas, donde cada una de ellas articula un fragmento interpretativo de la imagen que al sintetizarlos podremos dar con los hitos y el hilo de su base mitológica con la finalidad de comprender una visión concisa y enriquecedora para la valoración de la imagen.

Comenzando por el Renacimiento, una imagen idónea para el análisis sería el caso de las medallas conmemorativas en honor del matrimonio de Felipe II con María Tudor [1], convenio por el cual él accedería vía iure uxoris ${ }^{2}$ a la corona de Inglaterra e Irlanda. En esta imagen donde el Rey se muestra por el anverso, mientras que en el revés hay una representación de la biga de Apolo. Antes de adentrarnos de lleno al análisis, es imprescindible la contextualización partiendo de lo general a lo particular.

\footnotetext{
${ }^{2}$ Locución latina de "por el derecho de su consorte".
} 


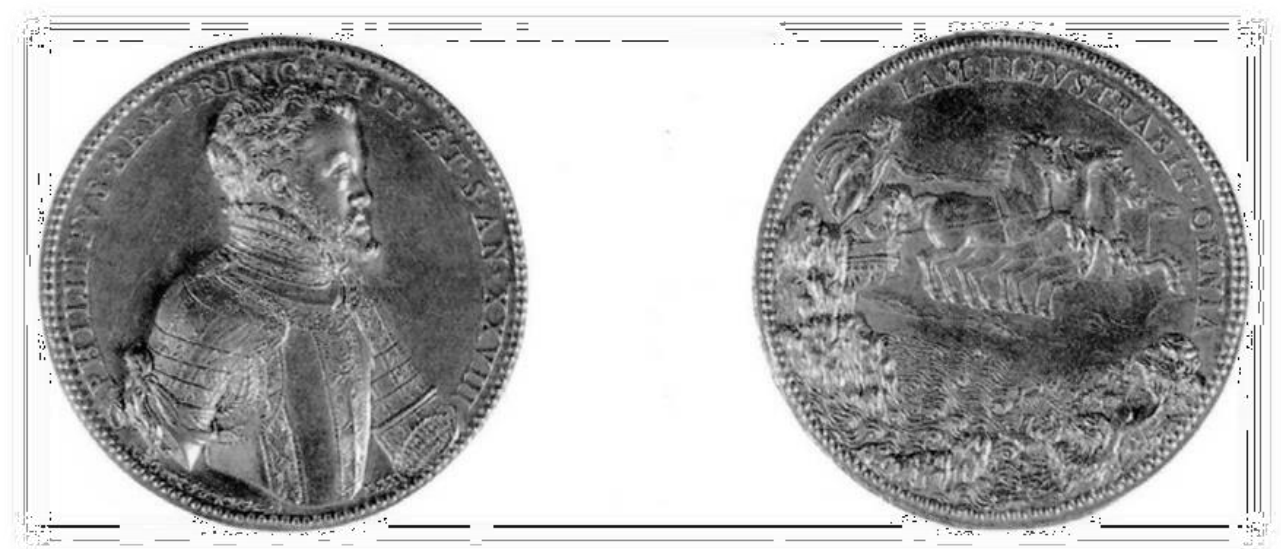

1. Medalla de Felipe II como príncipe de España y Rey de Inglaterra, 1555. Fuente; Londres, Victoria \& Albert Museum [Inv. 6759-1860]. Madrid, Museo del Prado [Inv. 44].

Estabilizado el reino español de Felipe II, tanto en Europa como en América, éste requeriría de una imagen que sintetizara su posición como monarca múltiple por ser Duque de Milán; Rey de Nápoles; Rey de Inglaterra e Irlanda; Soberano de los Países Bajos y Duque de Borgoña; Rey de España, Sicilia y las Indias, así como también Rey de Portugal.

Puntualmente, previamente al Renacimiento, gran parte de las referencias iconográficas de la monarquía se limitaban casi exclusivamente a la (re)interpretación de los textos bíblicos, con los cuales se estableció un primer esbozo de orden moral en los valores sociales transmitidos por dichas imágenes; no obstante, la construcción iconográfica del Renacimiento habría de darse por medio de méritos fortuitos, debido a que la búsqueda de esta nueva idea de representación encontraría un punto determinante para su definición con el hallazgo de obras clásicas en las antiguas ciudades de Herculano (1738) y Pompeya (1748), ambas cerca de Nápoles, Italia. Con su visualización y estudio, no sólo se dio pie a la recuperación de una parte vital en la historia del hombre, sino también establecer un nuevo código estético, especialmente para la representación de los valores artísticos y socio-políticos de la época (Carmona, 2013, p.228) pero, sin llegar a competir con los preceptos religiosos -a pesar de que en ambos puntos la figura central era el hombre- debido a que para este momento, como indica Carmona, se caracteriza por “...tomar como modelo a alguien que con anterioridad haya sido alabado y celebrado, conservado siempre ante los ojos sus actividades y sus acciones" (Ídem.), hecho que podría ubicar a una persona a la altura de la historia a partir de una “...simbiosis entre paganismo y moral cristiana" (Ibíd. p.232), la cual reconfiguraría y establecería una serie de valores, código iconográfico que sería aprovechado por las monarquías europeas como la francesa o la española para la difusión de su presencia a lo largo de sus reinos. 
Ahora, en el análisis de similitudes, comencemos por Convenientia. En ella, la figura de Felipe II sacó provecho de la de Apolo a partir de la base mítica de que los gobernantes habían sido descendientes, o si no designios, de los dioses, hecho pactado en la Aemulatio con respecto a sus funciones que la deidad tenía (Ibíd., pp.31-32) en contraste con las del monarca español:

- Dios oracular: lo ve todo. Tal alusión recae por el hecho de la extensión de su reinado a lo largo de Europa, América, Asia y África.

- Dios de la música y el arte: custodio de algunos de los más reconocidos artistas de la época nombrada el Siglo de Oro gracias a su educación.

- Dios sanador, legislador y protector de los hombres: más que el primero, Felipe II apuntaló más los siguientes por la modernización y refuerzo de la administración monárquica, hecho relacionado a lo ocular, al centralizar la supervisión de estos, además de que en la época se introdujeron los ideales humanistas por medio de Tomás Moro y Erasmo de Rotterdam.

En el caso de la Analogía, en la medalla destaca "la leyenda Iam illustrabit omnia, <<a partir de ahora yo iluminaré el mundo>>" (Ibíd., p.232) con la cual Felipe II trata de emular la identificación de Apolo con el sol; un modo -quizás poco- sutil de presentarse como el sucesor del dios griego.

Finalmente, en síntesis, la Sympathia de Felipe II puede condensarse en el hecho de que su momento histórico fue considerado el amanecer de una nueva época, la cual sacaría a la humanidad de la oscuridad medieval para conducirla hacia el horizonte; siendo éste un ser desafiante, elegante y cultivado, elementos que le darían a su imagen un alto pedestal en la historia a nivel mundial en comparación con predecesores y sucesores.

\section{Tránsito metamórfico del Modernismo}

Ahora, para el Modernismo, la cuestión de elegir un caso es compleja debido a que desde la perspectiva socio-política no hubo una figura global como la de Felipe II porque para este momento gran parte de las naciones eran independientes y democráticas; sin embargo, en la senda del arte hay varios puntos en común que sí cumplen tal axioma. 
Como se anticipó, en este momento se suscitaron tensiones y rupturas en los círculos del arte y la economía. Específicamente en la primera, las academias balanceaban -unas con mayor dificultad que otras por los aspectos socio-políticos propios de sus naciones- la tradición y la vanguardia, por lo que gran cantidad de alumnos al abandonarle o en su defecto concluir sus estudios se inclinaron más por desafiar la usanza preestablecida como el neoclásico para experimentar para la creación y desarrollo de nuevos métodos de expresión. Con las emociones obtuvieron el Romanticismo (17901848), el Realismo (1840-1880), el Impresionismo (1874-1886), el Postimpresionismo (1886-1900); los estudios históricos dieron otras corrientes dependiendo de los textos, por ejemplo: las crónicas de viaje al Orientalismo (1798-1914) o los estudios de artistas al Prerrafaelismo (1848-1900). En algunos casos como el Simbolismo (1880-1910) colisionaron los estudios iconográficos con un sentido emocional y estético que resultó en el desarrollo de (re)interpretaciones y nuevas construcciones discursivas. A pesar de la amplitud de las posibilidades gráficas encerradas dentro del Modernismo, cada una pudo aportar un grano de arena a la playa de la economía, ya que su participación también tuvo gran enfoque en la difusión de valores socio- políticos, pero más que nada en los socioeconómicos a partir de la instauración y proliferación de la publicidad.

A partir de estos puntos se repetirán el mismo proceso de análisis conceptual. En la Convenientia, las distintas vertientes del Modernismo aprovecharon el hecho de que los mitos, según Kerényi: “...se alejaban, devenían remotos y menos comprensibles; pero continuaban en el corazón del universo mental, religioso e ideológico" (2009, p.14). Por tal motivo en las figuras literarias, pictóricas y escultóricas de algunas corrientes artísticas, en Aemulatio del neoclásico, se hicieron de elementos iconográficos de los mitos para (re)producir sus obras, como el Orientalismo [2], hecho descrito por Crepaldi:

"Los artistas quedaron impresionados por la belleza natural de los lugares agrestes en donde sobrevivían los vestigios de las grandes civilizaciones del pasado... describen los lujosos palacios... la vida sencilla del pueblo... caravanas nómadas del desierto, escenas de caza, fiestas, ceremonias religiosas y el sensual erotismo de las odaliscas en los harenes" (2005, p.28). 


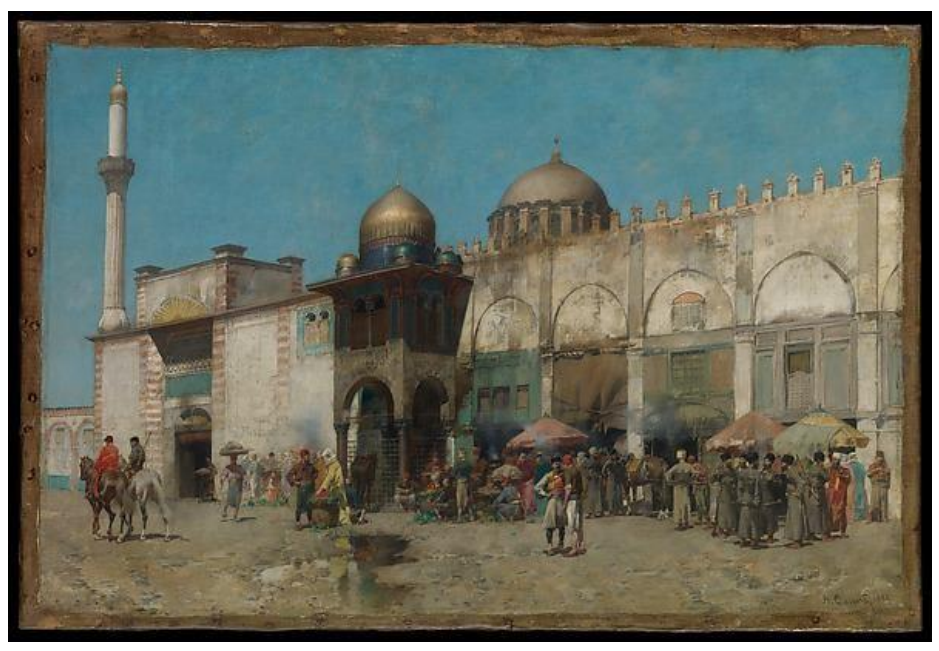

2. A Mosque, Alberto Pasini, 1886. Óleo sobre lienzo, 37.1 x $55.2 \mathrm{~cm}$, The Metropolitan Museum.

A partir de ello, en la Analogía los Simbolistas [3] tomarían la batuta debido a que en sus obras, los atributos impregnados en sus obras para dar un sentido de libertad de las convenciones culturales; una apertura del panorama con -casi- las mismas palabras que les aprisionaban. Para ello habría que considerar el comentario de Innerarity:

"En los orígenes de la modernidad, el espíritu se inventa una estrategia para apresar la naturaleza entera, para compensar lo prosaico con la naturaleza como huella, como rastro, como símbolo de lo divino; la poesía se abre paso frente a la conspiración universal de trivializar las cosas y, deseando huir de la artificialidad, el hombre goza estéticamente de la naturaleza, olvidando por un momento que todo arte es un artefacto humano, un invento de la cultura dirigido a salvar por medio de la ficción el abismo infranqueable entre la inocencia y la libertad". (1992, pp.522523) 


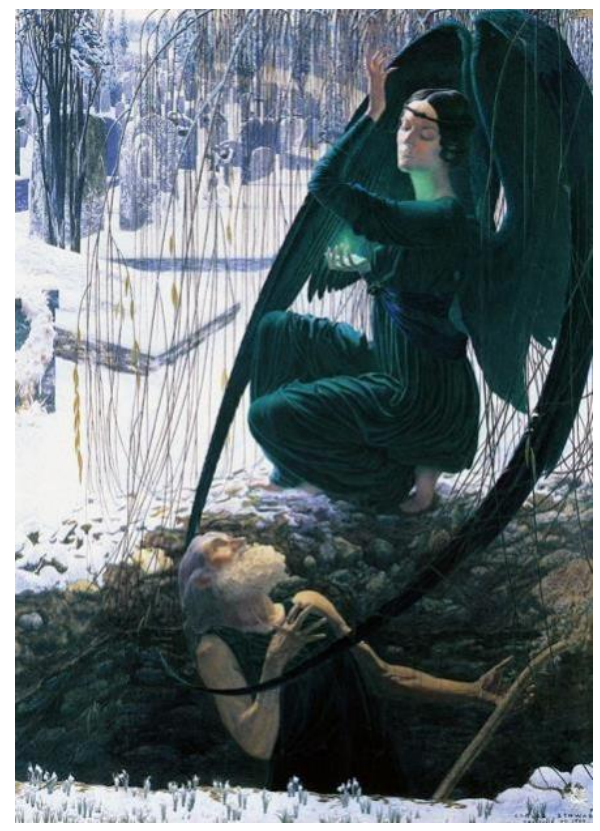

3. La mort du fossoyeur, Carlos Schwabe, 1895. Acuarela, 75 x $55.5 \mathrm{~cm}$, Louvre Musee.

En la sumatoria de estos puntos, la referencia de la publicidad del modernismo sería la Sympathia ya que en el Art Nouveau [4], género artístico de finales del siglo XIX y principios del XX, como crisol de las diversas corrientes modernistas sería considerado el vehículo vinculador, la lengua unificadora, de una generación consolidada en la globalización.

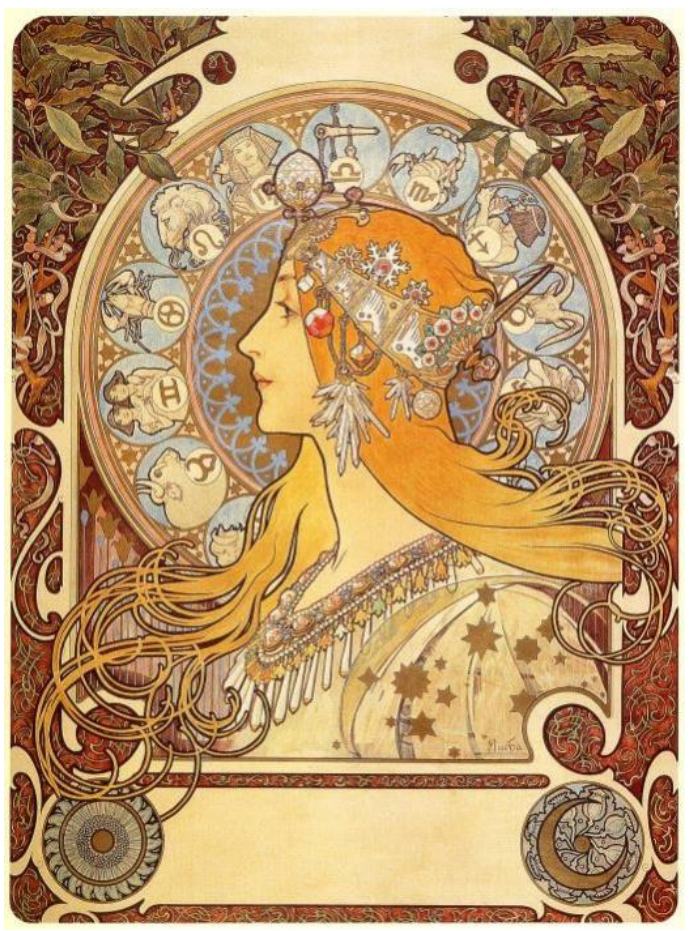

4. Zodiac, Alfons Mucha, 1896. Linografía a color, 65.7 x 48.2 cm, Mucha Museum. 


\section{Conclusiones}

Del mismo modo en que el Renacimiento fue el nuevo cuerpo de las formas clásicas y el Modernismo el de una extensa suma de recapitulaciones, queda decir que la metamorfosis, como estos momentos pueden apreciarse como fenómenos cíclicos a manera de uróboros [5], donde la cabeza del hombre se consume así mismo desde los pies -los fundamentos, el pasado- para poco a poco generar o en su defecto regenerarse infinitamente, no en un nuevo cuerpo sino en sí mismo. Sin embargo, tal proceso no está supeditado a un protocolo preestablecido, sino que será a partir de las aspiraciones y factores presentes que se propiciarán la sentencia del cambio, el cual, a final de cuentas es inevitable, visión corroborada por Perilli:

“... al crear relaciones se forman imágenes como motivos portadores de una significación convencional. La imagen es relación, vehículo entre conceptos, metáfora...Toda figura retórica, toda poiesis, es decir todo acto, todo hacer, es la proyección del código verbal y, antes del código, de la epifanía verbal, al mundo sensible de las cosas percibidas, de las cosas vistas" (2008, p. 21).

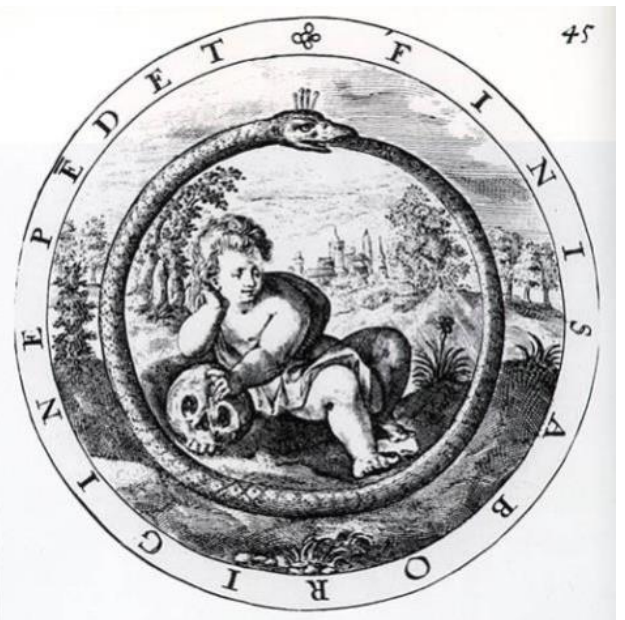

5. Illvstr. XLV, George Wither, 1635. Fuente: A collection of emblemes, ancient and moderne quickened with metricall illustrations, both morall and divine: and disposed into lotteries, that instructio, and Good Consell, may be furthered by a honest and pleasant recreation. Emblem Collection at Urbana-Champaign Library, University of Illinois.

Por tanto, la presente propuesta de análisis e interpretación iconográfica muestra pertenencia con el espíritu del cambio visto en la metamorfosis. La noción de que las imágenes encierran múltiples significados es lo que debe seguir impulsando este tipo de reflexiones, porque dependerá del tipo de llave, ya sea simple o intrincada, con la cual se traten de ceder las cerraduras que 
envuelven la complejidad, multidisciplinariedad y transversalidad de los discursos gráficos que nos han acompañado desde los confines del tiempo, mismos que seguirán estando entre nosotros después de que partamos. Por ello, las próximas generaciones de artistas, arquitectos, historiadores, museógrafos, restauradores de bienes, entre otros tantos, deben contar con el bagaje más completo para que entre sus valoraciones sigan permaneciendo los rastros de los ideales transmitidos por las obras del Renacimiento y el Modernismo que a pesar de haber cambiado con el tiempo, parte de sus valores continúan inmanentes.

\section{Referencias bibliográficas}

CARMONA MUELA, Juan (2013) [2000] Iconografía clásica Guía básica para estudiantes, Básica de bolsillo No. 156, Akal/Istmo, Madrid, España.

CASADO PÉREZ, Francisco José (2017) Principios y criterios para la valorización y conservación de la vivienda modernista en la Ciudad de México, Tesis de maestría en Conservación y Restauración de Bienes Culturales Inmuebles, Escuela Nacional de Conservación, Restauración y Museografía "Manuel del Castillo Negrete”, Ciudad de México, México.

COVARRUBIAS, Javier (2010) Del Neoclásico al Movimiento Moderno, un momento en el respirar de la forma. Colección Polémica No. 8, Serie: Arquitectura, complejidad y ornamento Vol, I. D.F., UAM Azcapotzalco, México.

CREPALDI, Gabriele. (2005) [2004] El siglo XIX, Rosa Solà, Los Siglos del Arte, Electa (Grupo Editorial Random House Mondadori, S.L., Barcelona, España.

FOUCAULT, Michel (2005) [1966] Las palabras y las cosas, Siglo XXI Editores, México.

INNERARITY, Daniel. (2008) Ética de la hospitalidad, Ediciones Península, España.

JUNG, C. G.; KERÉNYI, Karl (2004) Introducción a la esencia de la mitología: el mito del niño divino y los misterios eleusinos. Biblioteca de Ensayo, Ediciones Siruela, S. A., Madrid, España.

KERÉNYI, Karl (2009) [1958] Los héroes griegos. Ediciones Atalanta, Girona, España.

LEYVA, José Mariano (2013) Perversos y pesimistas: Los escritores decadentes mexicanos en el nacimiento de la modernidad. Colección Tiempo de memoria, Tusquets Editores, México. 
PERILLI, Marco (2008) El Artesano de la Verdad: ensayo sobre la imaginación, Autoría I, Taller Ditoria - CONACULTA, Ciudad de México, México.

VILLORO, Luis (2015) [1992] El pensamiento moderno. Filosofía del Renacimiento, Colección Centzontle, FCE - El Colegio Nacional, México. 